\title{
Reflexiones sobre patriarcalismo y discapacidad: una mirada desde el ámbito educativo*
}

\author{
Reflections on Patriarchy and Disability: A Look from the Educational Field \\ Diana Patricia García Ríos ${ }^{1}$
}

Para citar este artículo: García, D. P. (2017). Reflexiones

sobre patriarcalismo y discapacidad: una mirada desde el ámbito educativo. Infancias Imágenes, 16(2), 305-312.

\section{Resumen}

Artículo de reflexión que busca incitar la consciencia individual y social sobre los efectos del modelo patriarcal en el sistema educativo, de manera particular en la educación de las personas en situación de discapacidad. Se describen algunas características de la cultura patriarcal y las formas de actuación que ha instaurado en el ámbito educativo, configurándose como mecanismo de control, dominación y exclusión de los sujetos y de la vida misma. El artículo resalta la necesidad de propiciar una educación incluyente pensada desde una ética del cuidado y desde una perspectiva de educar para cuidar la vida; enfoques que invitan a desplegar la subjetividad y la conexión con la vida desde experiencias pedagógicas que vinculen la amorosidad, el cuidado mutuo, la solidaridad y la aceptación de la diferencia como elementos esenciales que deben incorporar los procesos pedagógicos. Se propone avanzar hacia una educación otra donde todos y todas sean aceptados $\mathrm{y}$ acogidos sin distinciones $\mathrm{y}$ exclusiones.

Palabras clave: discriminación; segregación escolar; educación especial; cultura dominante; aprendizaje a través de la experiencia; educación alternativa.
Recibido: 13-enero-2017 / Aprobado: 01-octubre-2017

\begin{abstract}
Reflection article aimed at inciting individual and social awareness about the effect of patriarchal model in the education system, particularly in the education of handicap people. The patriarchal culture characteristics are described and shows ways of action that has been established in the educational area configured as a mechanism of control, domination and exclusion of subjects and life itself. The article highlights the need to promote inclusive education designed from a care ethic and from educating for life care perspective, approaches that invite deploy subjectivity and connection to life from educational experiences that link love, mutual care, solidarity and acceptance of difference as essential elements that must incorporate the pedagogical processes. It is proposed to move towards an education where everyone is accepted and welcomed without distinctions and exclusions.
\end{abstract}

Keywords: discrimination, school segregation; special education; dominant culture; experiential learning; alternative education.

\footnotetext{
* Artículo de reflexión teórica resultado del proceso de formación doctoral.

1 Psicóloga, Magister en Educación con énfasis en Educación Comunitaria y estudiante del Doctorado en Educación con especialidad en Mediación Pedagógica de la Universidad de la Salle de Costa Rica. Docente de planta de la Licenciatura en Pedagogía Infantil, Universidad Distrital Francisco José de Caldas. Correo electrónico: dianapatriciasecret@gmail.com
} 


\section{Incertidumbres en torno al patriarca-} lismo y la educación

El ser humano evolucionó como ser vivo a partir de un proceso biológico y cultural que configuró su forma de ser y estar en el mundo. Bajo este panorama, su vida se desenvolvía en el emocionar y conversar trasegando por senderos de apoyo, cooperación y solidaridad mutua que fluían y se desplegaban en el lenguajear y convivir con los otros y con lo otro. Estos ejercicios relacionales dieron vida a un linaje que era transmitido de generación en generación, caracterizando así una primera cultura: la cultura matrística (Maturana, 2007). Este fue el estilo de vida de los antiguos pueblos europeos.

La cultura matrística prepatriarcal privilegiaba redes conversacionales de participación, inclusión, colaboración, comprensión, acuerdo y coinspiración. El respeto mutuo, el cuidado y la no violencia eran su modo cotidiano de coexistir y de vivir en comunidad. Se establecían relaciones sustentadas en el vínculo y la afiliación, dejando de lado las jerarquías y el uso del poder y del control como fuentes de dominación (Eisler, 2000; Maturana, 2007).

Según Eisler (2000), hacia el V milenio a. C. esta forma de vivir fue interrumpida por una serie de invasiones y migraciones de pastores esteparios o kurgos $^{2}$, quienes de manera abrupta impusieron dispositivos de convivencia y de relación centrados en la conquista, la guerra y la dominación de los otros; los cuales cambiaron la cultura y formas relacionales de los antiguos pueblos europeos. Se instaló así una cultura distinta y una red conversacional que favorecía valores como la destrucción de la naturaleza, la apropiación de recursos, la competencia, la enajenación, la subordinación y segregación de los otros. Valores que transformaron la convivencia de las antiguas sociedades matrísticas y dieron origen a la cultura patriarcal que aun hoy permanece instalada en nuestro colectivo social y que pone en peligro la pervivencia de la humanidad y del planeta mismo (Maturana, 2007).

La cultura patriarcal ha impregnado los intersticios de nuestra vida y paulatinamente ha expandido su dominio a todas las esferas de la realidad. Está presente en la ciencia, la salud, la economía, la política, el arte, la educación y demás dimensiones de actuación de las sociedades modernas.
En la dimensión educativa la cultura patriarcal se ha desplegado en diversos escenarios y contextos. Se evidencia, por ejemplo, en el tipo de relaciones pedagógicas que se instauran, pues promueve la exclusión de unos y el acceso de otros al ámbito escolar. Solo los más fuertes, los considerados productivos, los que se ajustan los estándares de normalidad, ingresan sin restricción al sistema escolar; mientras que aquellos considerados débiles, vulnerables o poco inteligentes son segregados y relegados a modalidades de educación compensatoria cuyo propósito primordial es normalizarlos, volverlos funcionales.

Este aparato educativo patriarcal promueve la competencia, la cohersión, el autoritarismo, el rechazo, la fragmentación del conocimiento, el culto a la teoría y a las verdades universales y deja de lado la subjetividad, la espiritualidad y la vida cotidiana como elementos esenciales para la formación de los educandos.

A la hora de organizar los procesos formativos, el establecimiento educativo impone y define los planes de estudio, los recursos económicos, los apoyos didácticos y los parámetros de evaluación de educadores y educandos. Toda esta infraestructura escolar es configurada de manera diferenciada: lo de mayor calidad para los más privilegiados; lo accesorio y remedial para aquellos en situación de desventaja social. Lo anterior, propicia situaciones de competencia, inequidad y negación de los sujetos, aspectos que perpetúan dinámicas de opresión y exclusión que afectan negativamente a la población en general y a la población en desventaja social en particular.

El trabajo de aula está sustentado en la autoridad del maestro. Él es quien dirige, selecciona y transmite los contenidos y propósitos del aprendizaje; impone los protocolos de actuación, aprueba las formas de participación, establece las normas para convivir y para aprender. Los aprendientes se consideran seres pasivos que deben ser receptores obedientes de lo dispuesto por el maestro y su obligación es reproducir contenidos, aunque estos no resulten significativos para su existencia, ni relevantes para desenvolverse en su entorno natural.

La educación patriarcal privilegia la competencia, la confrontación, la racionalidad, el 
individualismo. Se educa para la rivalidad, para el consumo y para la obtención de privilegios, a costa de la negación y opresión de los otros y de la destrucción de la naturaleza. Recrea formas de ser y estar en el mundo que niegan el ser y desfiguran el hacer, marginan las expresiones de afecto, la reciprocidad y la solidaridad enfermando el espíritu y restringiendo la autonomía y confianza en sí mismo. Es una educación que no admite las propias reflexiones y que criminaliza la diferencia, el amor, el placer y la emoción al tiempo que ignora la polifonía de identidades, interacciones e interrelaciones que circulan entre los aprendientes en los distintos escenarios de aprendizaje.

La población en situación de discapacidad no es ajena a las injusticias e inequidades que determinan una educación orientada desde el modelo patriarcal. Revisemos algunos elementos que la describen.

\section{Educación patriarcal y discapacidad}

El modelo de sociedad patriarcal ha fomentado una estructura de pensamiento binario y fragmentado que tiende a subordinar, rotular y clasificar a todos los seres humanos. Bajo la sombrilla de este modelo social todos debemos saber que el mundo se mira desde pares contrarios, excluyentes, separados y divididos. Es decir, los hombres son lo contrario de las mujeres, los ricos de los pobres, los indios de los blancos, los normales de los anormales, así pasa con todos los seres vivos que compartimos este hogar planetario.

Las personas en situación de discapacidad no escapan a esta clasificación que solo conduce a reforzar una serie de roles, prejuicios y estereotipos excluyentes que desafortunadamente están vinculados a esta visión dual del mundo y de los seres que hacemos parte del mismo. Bajo esta perspectiva, son consideradas enfermas, inútiles, dependientes, improductivas, incapaces, en otras palabras, "anormales". Y por supuesto siempre se las compara con los Ilamados "normales", es decir, los sanos, los útiles, los independientes, los productivos, los

\footnotetext{
2 Para más información sobre este proceso migratorio véase Eisler (2000), en donde se explica con detalle los choques culturales producidos por la migración y desplazamiento de estos pueblos en tres momentos diferentes de la historia.
}

capaces. Estas clasificaciones caracterizan algunos (por no decir muchos) principios de nuestra sociedad, los cuales configuran e imponen parámetros de actuación para perpetuar relaciones de poder, subordinación, obediencia, resignación, impotencia y minusvalía.

Como se puede apreciar, esta es la sociedad patriarcal en la que vivimos. Una sociedad que ha instaurado un sistema de relaciones jerárquicas y de dominación que están presentes en todas las esferas de la vida como: lo social, lo educativo, lo económico y lo político. Una sociedad que estimula y perpetúa la exclusión y la discriminación con la disculpa de proteger a los ciudadanos de los impactos negativos que produce la diferencia corporal, biológica, sexual y cultural. Se considera monstruo "todo aquel que desafía lo que debe ser, teniendo la osadía de ser diferente [...] la idea de que todo aquello diferente a nuestra normalidad es encarnación del peligro o del mal, se reproduce a lo largo de la historia humana" (Cajíao, 1997, pp. 19 y 20). La diferencia se considera una desviación, un fenómeno peligroso que pone en riesgo el ser y el sistema social que habitamos.

Es preocupante apreciar que los tentáculos del patriarcalismo se extienden a todas las esferas de la sociedad. Tal es así que cuenta con una red de instituciones o instancias sociales que estimulan las relaciones jerárquicas, que promueven la desigualdad, la segregación y la discriminación contra todas aquellas personas que el sistema ha considerado históricamente débiles, vulnerables, anormales y por supuesto, discapacitadas.

La educación, por ejemplo, es utilizada por el patriarcalismo y el modelo mecanicista como instrumento de control y subordinación. Esta se constituye en una de las instancias sociales estratégicas para perpetuar los valores y principios que deben alimentar y sostener el sistema. Veamos cómo ha sido el panorama, a propósito de la educación de personas en situación de discapacidad.

Aunque en las décadas recientes las políticas educativas dirigidas a las personas con discapacidad han cambiado bajo la perspectiva de evitar y disminuir la exclusión y la vulneración de los derechos de este sector de la población, aún persisten situaciones de discriminación que afectan su calidad de vida y la de sus familias. 
Los procesos educativos ofrecidos a las personas en situación de discapacidad se han instaurado a partir de los criterios de normalidad definidos por la cultura dominante. Como estas personas no se ajustan a los parámetros establecidos se les considera indeseables, ineptos y con poca o ninguna posibilidad de aprender. Por tal razón se cree que deben ser rehabilitados para alcanzar su normalización y lograr que se adapten, en lo posible, a los estándares de comportamiento y actuación establecidos por la sociedad. "En una sociedad como la nuestra, la normalidad es cada vez más restringida, cada vez más estereotipada y, por lo tanto, más intolerante" (Cajíao, 1997, p. 22).

Lo anterior permite entrever que los procesos de formación dirigidos a la población con discapacidad han enfocado la atención en sus carencias, sus dificultades, sus limitaciones para luego rotularlos y clasificarlos bajo la presunción de que son seres débiles, enfermizos, deleznables. Es decir, ciudadanos de segunda que además requieren una educación especializada para ser liberados de sus torpezas y falta de inteligencia. Como resultado de esta visión negativa y prejuiciosa se han generado infinidad de propuestas educativas compensatorias y asistencialistas que no aportan mucho a su ser humano, ni a su posibilidad de existir como legítimos otros; sino que han dedicado sus esfuerzos a normalizarlos, a adaptarlos $^{3}$. Según García y Jutinico, muchos investigadores expresan que

[...] esta tendencia a diagnosticar y etiquetar a las personas de acuerdo con su deficiencia ha producido un efecto negativo en su progreso escolar. Esto es cierto, porque calificar a un estudiante como deficiente y con dificultades para aprender, condiciona la expectativa del profesor frente a sus capacidades reales y lo induce a centrarse en aquello que no puede hacer, dejando de lado las demás características y capacidades de esa persona. (2014, p. 109)

\footnotetext{
Aunque hoy en día circulan variedad de discursos que enuncian lugares de reconocimiento y respeto por la diferencia, dichos discursos se revelan como ficciones que dan abrigo a la segregación y que de manera soterrada mantienen prácticas clasificatorias y de inferiorización que desafortunadamente sobreviven escondidas bajo el velo de una fingida o fallida inclusión.
}

Esta mirada especializada, clasificatoria y compartimentada de la discapacidad desconoce la dignidad de las personas y no permite visibilizarlas como seres integrales que habitan el mundo en permanentes interacciones, entrelazamientos e intercambios con sus pares y con la naturaleza; con posibilidades infinitas de tomar decisiones, expresar inconformismo, celebrar la diferencia y re-crear la trama de la vida en un ejercicio de cuidado y protección de sí mismo, de los otros y del planeta.

Los anteriores enunciados son razonamientos y expresiones típicas del modelo androcrático o patriarcal descrito por Eisler (2000), en el cual sobrevive el más fuerte, el que se ajusta a los parámetros de actuación de los considerados normales y legítimos para todos. En tal sentido, las personas en situación de discapacidad son calificadas como débiles e inútiles y deben ser normalizadas para que sean productivas para el sistema. Esta situación es un triste reflejo de cómo la educación para esta población ha centrado todos sus esfuerzos no solo en "rehabilitar" y "normalizar" a los sujetos, sino también en rechazarlos y señalarlos como culpables de su condición de debilidad, tal como lo dictan los cánones del modelo patriarcal. En esta frenética y árida carrera se ha olvidado que son seres encarnados con sentimientos, incertidumbres, deseos, miedos e inconformismos. Esta situación es un aspecto que evidencia lo que Boff (2002) denomina el fenómeno del descuido, la indiferencia y el abandono.

Es evidente que, en la mayoría de los casos, la educación para las personas en situación de discapacidad ha actuado en detrimento de su calidad de vida y ha reforzado los prejuicios y mitos que continúan la idea de la discapacidad como un problema o como una enfermedad; condenando a estas personas a vivir unas situaciones de vulnerabilidad, marginación y desventaja. García y Jutinico manifiestan que estas condiciones negativas de la educación se mantienen debido a

[...] la persistencia en unas prácticas centradas en la rotulación de los estudiantes y a la marcada insistencia en desarrollar el proceso educativo en un sentido homogenizante y normalizador, pretendiendo desaparecer la diferencia como elemento constitutivo 
del ser humano y propiciando de esta manera prácticas en las que se refleja el desconocimiento del otro. (2014, pp. 110 y 111)

Podría afirmarse que, desde el modelo patriarcal, la diferencia dispersa porque muestra otras formas de ser y estar en el mundo que no se ajustan al modelo dominante; solo se tolera la diferencia cuando se percibe que podrá ser eliminada. Es evidente que estas formas distintas de ser y estar en el mundo escapan a los dispositivitos de control que garantizan la obediencia y la subordinación y ponen en peligro la perpetuación del sistema androcrático, mecanicista, dual y excluyente que ha matizado los procesos formativos para esta población.

Aunque existen muchas propuestas educativas alternativas que plantean la necesidad de una educación para todos y todas (las cuales rescatan como indispensables conceptos y procesos educativos enmarcados en la solidaridad, el respeto del otro, la aceptación de la diferencia, la equiparación de oportunidades y la educación sin exclusiones), aún persisten situaciones de discriminación y segregación que no se han podido superar. La educación exige cambios en la forma de entender el fenómeno de la discapacidad, pues el problema no se sitúa en la persona y en sus dificultades sino en las barreras culturales, sociales y educativas que le impone la cultura dominante y que no le permiten vivir, aprender y participar en condiciones de equidad y justicia en su comunidad.

Cabe mencionar que este breve recorrido corrobora lo que ya sabíamos: que la educación ha sido utilizada como una de las estrategias del patriarcado para mantener este statu quo, reforzando los roles y estereotipos sociales contra las personas con discapacidad. De este modo, el modelo social que sufrimos y soportamos ha construido una telaraña ideológica que ha influido en el inconsciente colectivo de nuestra sociedad y que ha impedido que los cambios y transformaciones que se han intentado puedan tener mayor impacto.

No solo las personas en situación de discapacidad sufren las consecuencias y afectaciones del modelo patriarcal. Todos nosotros (mujeres y hombres) estamos enredados en una lógica conversacional que estimula el conflicto, la dominación de unos sobre otros, la competencia, el desapego, la envidia y la indiferencia. Como diría Boff (2002), estamos atrapados en una lógica enmarcada por la falta de cuidado, por el menosprecio de la solidaridad y por la desintegración de los ideales de dignidad y libertad para todos los seres humanos.

Es claro que no necesitamos una educación especializada para atender cada sector de la población. Es urgente soñar una educación para todos y todas que desnaturalice y elimine la coerción, la exclusión y la competencia. Debemos superar la idea de que necesitamos una educación para mujeres y otra para hombres, una para pobres y otra para ricos, una para indígenas y otra para mestizos, una para anormales discapacitados y otra para normales, etc. Lo que requerimos es una educación incluyente y amorosa que nos permita disfrutar nuestras experiencias de aprendizaje desde la diferencia y que nos ayude a avizorar nuevas formas de ser $y$ estar en el mundo en beneficio de nuestra calidad de vida y de nuestra dignidad humana. En otras palabras, los educadores debemos explorar y re-crear formas alternativas de educación que preparen en, desde y para la vida sin prejuicios y prevenciones de raza, genero, nivel social, condición económica o estilo de aprendizaje.

Educar sin exclusiones: educar para cuidar la vida

Como se ha descrito en este texto, la historia de la educación de las personas en situación de discapacidad visibiliza un ejercicio educativo deshumanizador, violento y abandónico. Este es un ejercicio educativo que no queremos perpetuar y para lograrlo es urgente admitir que debemos desarrollar la dimensión de anima que tenemos dentro. En palabras de Boff:

Eso significa reconocer pleno derecho a nuestra capacidad de sentir al otro, de tener compasión de todos los seres que sufren, humanos y no humanos, de obedecer más la lógica del corazón, de la cordialidad y de la delicadeza que la lógica de la conquista y del uso utilitario de las cosas. (2002, p. 84) 
Es urgente desligarnos de la dictadura del patriarcado y de sus parámetros de opresión, homogenización y exclusión, para avanzar hacia una educación más humanista que se ocupe de fomentar una ética del cuidado. Pues, según Boff, "en el cuidado identificamos los principios, los valores y las actitudes que convierten la vida en un vivir bien y las acciones en un recto actuar" (2002, p. 14).

Se hace necesario soñar una educación que incorpore la solidaridad, el amor, la com-pasión, el respeto por sí mismos, por los otros y por la naturaleza; valores imprescindibles para todos los seres de la creación. Una educación que abra sus puertas al cuidado y a la participación respetuosa y fraterna; de cada vez más personas. Una educación que se centre "[...] en la valoración de la diferencia, en la aceptación de las complementariedades y en la convergencia construida a partir de la diversidad de culturas, de modos de producción, de tradiciones y de sentidos de vida" (Boff, 2002, p. 26).

Los docentes y profesionales que laboramos en ámbitos de la educación y la discapacidad tenemos que abandonar nuestra indiferencia y desinterés por una ética del cuidado y enfrentar el reto de configurar una educación solidaria que demuestre y exprese actitudes y prácticas de preocupación, responsabilidad y compromiso afectivo por el otro. Una educación cuyo propósito esencial sea el cuidado, pues según Boff "el cuidado es una actitud de relación amorosa, suave, amigable, armoniosa y protectora de la realidad personal, social y ambiental" (2015, p. 53). Lo anterior implica soñar una educación que propicie espacios comunes para la reciprocidad, para la reflexión y para la colaboración, donde todos y todas (los privilegiados y los considerados vulnerables) recreen y encarnen experiencias solidarias y de reconocimiento del otro como legítimo otro. Dicho de otra manera, una educación que nos permita abrir nuestro espíritu a las invaluables posibilidades de cuidar, sentir, amar, proteger y nutrir a través de nosotros y en nosotros. Es decir, desplegar una educación con arraigo en las características de la cultura matrística.

Tendríamos que configurar escenarios y relaciones pedagógicas que puedan liberarnos de "nuestro modo de ser trabajo" y situarnos en un "modo de ser cuidado". ¿Por qué cambiar?, quizás porque el "modo de ser trabajo" nos ubica en el mundo, desde actitudes de dominación, explotación y exclusión dejando de lado la espiritualidad y el bien común; mientras que el "modo ser de cuidado" nos invita a compartir, desplegar, vincular y religar nuestros encuentros con el universo y con los otros (desde su diferencia) para sentirlos, acogerlos, respetarlos (Boff, 2002). En fin, nos conduce a estar en armonía con nosotros mismos, con los otros y con la naturaleza.

Requerimos escenarios pedagógicos que den lugar a un nuevo lenguajear y que nos permitan a todos y todas transitar por la trama de la vida sin temor a la exclusión, la opresión y el rechazo. Necesitamos una educación enriquecida con experiencias y actuaciones de co-participación y co-inspiración, porque el compartir con los otros hace posible construir comunidades de aprendizaje impregnadas de formas de convivencia amorosa, acogedora y gratificante. En otras palabras, permite "[...] crear, realizar y validar en la convivencia, un modo particular de convivir [...]" (Maturana, 2002, p. 147).

En tal sentido, los ambientes y escenarios pedagógicos deben dejar de ser espacios para la acumulación de contenidos y convertirse en lugares donde el placer y la creación sean la esencia de las experiencias de aprendizaje que se propician. El aprendizaje es ante todo una experiencia de vida en la que está implicado todo el ser del aprendiente, es por ello por lo que resulta indispensable brindar experiencias vitales y no solo información desligada de la propia existencia. En esta dirección Assmann afirma que "el conocimiento solo emerge en su dimensión vitalizadora cuando tiene algún tipo de vinculación con el placer" (2002, p. 29).

La educación no debe mirarse como un simple proceso de transmisión y reproducción de conocimientos predefinidos, sino que requiere ser concebida como el espacio propicio para encarnar el conocimiento desde experiencias relacionales que privilegien el aprender a aprender, el aprender a ser y el aprender a vivir. Ello significa vincular y ligar los procesos vitales con los procesos de conocimiento en conexión con la vida de los aprendientes.

La educación debe abrir sus puertas a la vida $y$ al afecto y desplegar, en el diario acontecer 
pedagógico, ejercicios y vivencias relacionales que admitan y celebren la subjetividad, la corporeidad, la emocionalidad, la incertidumbre, la confianza, la colaboración, la reciprocidad afectiva y la aceptación de la diferencia. Debemos avizorar una educación más humanista e incluyente que permita vivenciar los aprendizajes como actos significativos que tienen resonancia en la existencia y que permiten la transformación en la convivencia; "vale la pena el esfuerzo de humanizar las relaciones para que sean expresión de hospitalidad, de voluntad de convivencia con el otro, y de establecer lazos con lo diferente" (Boff, 2012, p. 87).

Los procesos formativos deben dar espacios para la participación de todos y todas sin distinciones ni exclusiones. Deben constituirse como escenarios que permitan vincular los procesos vitales con los diferentes contenidos y conceptos que se usan en diferentes áreas de conocimiento, de manera que, al ligarlos, ayuden a comprender el mundo y transformarlo desde las propias necesidades y potencialidades. Assmann (2002) afirma que aprender es vivir y que ese aprendizaje debe ocurrir en los relatos y aconteceres que encarnamos en la trama de la vida.

No solo aprendemos en la escuela o en el aula, también aprendemos en la casa, el parque, el barrio, la tienda, la biblioteca, el bosque, etc. Todos los contextos y momentos de nuestra existencia se configuran como oportunidades de aprendizaje y se constituyen como nichos vitales donde podemos dialogar, cooperar, disentir, reclamar, asombrarnos y jugar con la vida y el conocimiento; es decir, nos permiten sufrir, gozar y celebrar el aprender.

El proceso de educar y educarse ocurre en el devenir de nuestra existencia. Es decir, ocurre en nuestros encuentros y desencuentros con los otros; en nuestra relación con la naturaleza; en las alegrías y tristezas que encarnamos; en el rechazo y la aceptación de sí mismo y de los otros; en los conflictos y consensos que enfrentamos; en las dudas e incertidumbres que albergamos frente a las teorías, los conceptos y la vida; en el cuidado y la preocupación por lo propio y lo ajeno. Es por ello por lo que los educadores y educadoras debemos ser provocadores y cómplices de experiencias de aprendizaje que permitan la creación, la interrogación, la curiosidad y la posibilidad de transformar el mundo entrelazando, religando y desplegando múltiples formas de comprenderlo y de entramarlo con las teorías, conocimientos y prácticas que las experiencias de aprendizaje brindan. En otras palabras, que el aprender ocurre a partir de la historia y en el devenir de la vida de los aprendientes.

La cultura patriarcal y su impacto en la humanidad debe ser trascendida y superada porque se ha constituido en una forma de vida que fragmenta $y$ aísla a las personas generando formas relacionales antagónicas, hostiles y excluyentes que han enfermado nuestra sociedad. Nuestro reto como educadoras y educadores es liderar prácticas educativas que permitan desterrar los procesos formativos de los vicios del patriarcalismo o, como diría Eisler (2000), de los poderes destructores de la espada y embarcarnos en la nave de la transformación cultural y su principio de vinculación, situando nuestro actuar en nuestra experiencia vital y en nuestro compromiso de educar y educarnos. Con acciones pequeñas y sutiles seguro se alcanzarán cambios que permitan recuperar el poder del cáliz, es decir, el poder de cuidar, nutrir, amar, proteger y comprender. Quizás esto es lo que necesita incorporar la educación para garantizar la calidad de vida y el bien-estar de todos y todas. Como diría Assmann (2002), necesitamos reencantar la educación.

Lo anterior supone favorecer procesos formativos centrados en una educación en, desde y para la vida, a partir de ejercicios relacionales de apoyo y cuidado mutuo que faciliten el convivir, encarnando, como lo propone García:

[...] ambientes de aprendizaje incluyentes que trasciendan la simple recepción de información y que permitan tejer, aprehender, vincular y aplicar lo aprendido con la existencia [...]. Ello significa generar experiencias vinculantes donde el aprendizaje ocurra en espacios habitados y desde la interacción entre subjetividades diversas, sin necesidad de negar, marginar o invisibilizar a los demás [...]. (2016, pp. 277 y 278$)$

Es innegable que los educadores tenemos la responsabilidad social de avanzar hacia propuestas educativas más incluyentes, flexibles y holísticas que reconozcan y revitalicen otras identidades, otros 
saberes, otras miradas del mundo, otras formas de ser y hacer. Otras formas de educar que nos permitan construir comunidad, generar redes de solidaridad y garantizar vivencias y escenarios de aprendizaje impregnados por la hospitalidad, el diálogo, la cordialidad, la cooperación y el reconocimiento del otro como interlocutor legitimo desde su diferencia. Necesitamos una educación que permita vivenciar la hospitalidad en la relación con los otros, como afirma Skliar:

[...] una hospitalidad sin condición, una hospitalidad que no pide nada a cambio. Una hospitalidad que no haga al otro un deudor eterno de una deuda que, siempre será impagable. Por eso, tal vez acoger al otro en la educación sea más bien recibirlo sin importar su nombre, su lengua, su aprendizaje, su comportamiento, su nacionalidad. (2009, p. 151)

Por ahora, solo me queda decir que las reflexiones compartidas en este escrito intentan abrir y consolidar espacios de formación que reconozcan como sustento esencial de los procesos pedagógicos, en la perspectiva de fortalecer la construcción de una sociedad más solidaria y hospitalaria que destierre la discriminación, violencia y la cohersión como formas relacionales características de nuestro ser y estar en el mundo. Es una invitación a mis colegas docentes para que sueñen y emprendan una educación que permita revitalizar, día a día, la dignidad de nuestro ser humano y nutrir desde una ética del cuidado, la incierta pero maravillosa experiencia de aprender y convivir.

\section{Referencias}

Assmann, H. (2002). Placer y ternura en la Educación. Hacia una sociedad aprendiente. Madrid: Narcea.

Boff, L. (2002). El cuidado esencial. Ética de lo humano. Compasión por la Tierra. Madrid: Trotta. . (2012). El cuidado necesario. Madrid: Trotta. (2015). Derechos del corazón. Una inteligencia cordial. Madrid: Trotta.

Cajíao, F. (1997). En las fronteras de la normalidad: un llamado ético para evitar el maltrato en la escuela. Bogotá: Norma.

Eisler, R. (2000). El cáliz y la espada. Nuestra historia, nuestro futuro. Santiago de Chile: Cuatro Vientos.

García, D. P.; Jutinico, M. S. (2014). El tránsito de la educación especial a la educación inclusiva: sendas diferenciadas en el entorno educativo. Revista Educación y Ciudad, 26. Bogotá: Cooperativa Editorial Magisterio.

García, D. P. (2016). Ambientes de aprendizaje incluyentes. Reflexiones desde una educación para la vida. Infancias Imágenes, 15(2), 271 279. DOI: https://doi.org/10.14483/udistrital. jour.infimg.2016.2.a08

Maturana, H. (2002). Transformación en la convivencia. Santiago de Chile: Dolmen Ediciones. . (2007). Amor y juego. Fundamentos olvidados de lo humano. Desde el patriarcado a la democracia. Chile: J. C. Sáez Editor.

Skliar, C. (2009). Fragmentos de experiencia y alteridad. En C. Skliar; J. Larrosa (comps.). Experiencia y alteridad en educación. Rosario: Flacso Argentina-Ediciones Homo Sapiens. 